\title{
RANCANG BANGUN PROTOTYPE ALAT PENJEMUR PAKAIAN OTOMATIS BERBASIS ARDUINO UNO
}

\author{
Alhen Dwi Darusman \\ Fakultas Teknik, Program Studi Teknik Elektro \\ Universitas Muria Kudus \\ Email: alhendwi@gmail.com \\ Mohammad Dahlan \\ Fakultas Teknik, Program Studi Teknik Elektro \\ Universitas Muria Kudus \\ Email: moh.dahlan@umk.ac.id \\ F. Shoufika Hilyana \\ Fakultas Teknik, Program Studi Teknik Elektro \\ Universitas Muria Kudus \\ Email: farah.hilyana@umk.ac.id
}

\begin{abstract}
ABSTRAK
Dalam penelitian yang berjudul prototype alat jemuran otomatis menggunakan sensor LDR dan sensor hujan berbasis Arduino Uno bertujuan untuk memudahkan pekerjaan manusia dalam masalah menjemur pakaian, karena apabila musim hujan tiba dimana ada pakaian yang dijemur dan lantas turun hujan pengguna tidak perlu khawatir karena alat penjemur pakaian otomatis ini akan secara otomatis bergerak menuju ke dalam ruangan. Metode yang digunakan adalah rancang bangun, yang diawali dari pembuatan prototype jemuran otomatis, membuat sistem kendali intensitas cahaya dan tetes air hujan sesuai dengan kebutuhan pada proses penjemur pakaian. Proses deteksi menggunakan sensor hujan dan LDR (Light Dependent Resistor), untuk indikator menggunakan LED. Pengendali yang akan digunakan berbasis Arduino Uno dengan Mikrokontroller ATmega 328 dengan bahasa pemrogaman, yaitu bahasa C. Dari hasil perancangan diketahui bahwa rangkaian dapat bekerja dengan baik yaitu ketika cuaca cerah jemuran pakaian berapa diluar ruangan dan ketika cuaca mendung atau hujan jemuran pakaian bergerak masuk ke dalam ruangan tertutup. Hal ini terlihat dari sensor dapat bekerja dan outputnya seperti LED dan kipas angin berfungsi (aktif). Pada saat pengambilan data, memakai cahaya ruangan untuk menstabilkan nilai multimeter.
\end{abstract}

Kata kunci: arduino uno, penjemur pakaian, sensor ldr, sensor hujan.

\begin{abstract}
This research is about prototype of automatic clothesline tool with LDR sensor and rain sensor based on Arduino Uno. which aims to facilitate the work of humans in the problem of hanging clothes, because when the rainy season comes where there are clothes that are dried and then rain, humans do not have to worry because this automatic clothes drying tool will automatically move into the room. The method used is the design, which started from the manufacture of automatic clothesline prototype, making the system of light intensity control and rain water drops in accordance with the needs of the clothes drying process. The detection process uses rain sensor and LDR (Light Dependent Resistor), for indicator use LED. The controller will be used Arduino Uno based with Microcontroller ATmega 328 with programming language, that is $C$ language. From the design result is known that the circuit can work well that is when the weather is sunny, clothelines get to move outside the room and when the weather is cloudy, or rainny, the clotheslines enter into a closed room. This is visible from the sensor can work and its output like LED and fan can work (active). At the time of data collection, room light is used to stabilize the value of multimeter.
\end{abstract}

Keywords: arduino uno, clothes dryer, light sensor, rain sensor. 


\section{PENDAHULUAN}

Seiring dengan kemajuan jaman dan semakin sibuknya manusia, maka seringkali masalah- masalah rumah tangga jadi terabaikan dan tidak dapat ditangani dengan baik, misalnya saja masalah penjemuran pakaian. Masalah ini terutama dihadapi oleh para pengguna flat atau apartemen. Mayoritas pengguna apartemen adalah orang-orang dengan tingkat kesibukannya yang tinggi sehingga seringkali masalah penjemuran pakaian terabaikan. Akan lebih merepotkan lagi apabila musim penghujaan tiba. Dimana saat pemilik rumah tidak ada didalam rumah, sementara ada pakaian yang dijemur dan lantas hujan turun. Tentu para penghuni rumah akan merasa cemas seandainya pakaian yang sudah dicuci dengan susah payah kembali basah tersiram air hujan begitu saja. Belum lagi apabila baju yang telah dijemur berhari-hari sudah benar-benar kering, namun para penghuni rumah merasa malas atau tidak ada waktu untuk melipat jemuran. Ketidakpraktisan ini sudah pasti menjadi problem tersendiri bagi individu yang menghuni tempat-tempat apartemen yang sangat peduli dengan masalah waktu dan kepraktisan suatu alat.

Dari penelitian Arif Budi Laksono dan Zaenal Abidin, menjelaskan tentang alat jemuran otomatis yang cara kerjanya adalah jika sensor cahaya mendeteksi adanya cahaya maka motor akan berputar dan menarik tambang keluar, sehingga posisi jemuran berada diluar, dan jika sensor cahaya tidak mendeteksi adanya cahaya maka motor akan menarik tambang jemuran untuk masuk, sehingga posisi jemuran berada didalam[1]. Dalam proses ini maka ketika jemuran berada didalam tidak ada proses pengeringan pakaian dikarenakan tidak terkena sinar matahari atau sinar lainnya (kondisi hujan). Penelitian Monilia Sitophila, Heriyanto, dan Samsul Hidayat, menjelaskan tentang atap sirip otomatis menggunakan pengontrol mikrokontroller ATMega8. Cara kerjanya adalah ketika sensor cahaya (LDR) mendeteksi adanya cahaya maka atap sirip akan membuka atau bergeser dan jika sensor tetes air hujan mendeteksi adanya air hujan yang turun maka atap akan bergeser dan menutup ruangan (jemuran didalam ruangan diam atau tidak bergerak) [2]. Dalam proses ini atap sirip menggunakan media fiber jadi sangat dihawatirkan rawan bocor atau rusak ketika terkena angina kencang pada waktu hujan dan tidak ada proses pengeringan di dalam ruangan.

Selanjutnya penelitian oleh Eko Rismawan, Sri Sulistyanti, dan Agus Trisanto, menjelaskan tentang alat penjemur pakaian otomatis yang menggunakan mikrokontroller ATMega8535 sebagai pengontrol [3]. Pada pengamatan kali ini diketahui bahwa rangkaian hanya menggunakan sensor air hujan dan tidak menggunakan sensor cahaya (LDR), maka rangkaian hanya akan bekerja dari ada tidaknya air hujan dan tidak ada proses pengeringan di dalam ruangan. Penelitian Elly Mufidah, Siti Nurajizah, dan Abdul Abas, yang menjelaskan tentang sistem buka tutup atap jemuran menggunakan sensor cahaya (LDR) dan sensor hujan, Cara kerjanya adalah ketika sensor cahaya (LDR) mendeteksi adanya cahaya maka atap sirip akan membuka atau bergeser dan jika sensor tetes air hujan mendeteksi adanya air hujan yang turun maka atap akan bergeser dan menutup ruangan (jemuran didalam ruangan diam atai tidak bergerak). Dalam penelitian ini mungkin lebih rumit dalam pemrogramannya karena menggunaka mikrokontroller ATMega16 yang memang dalam pemrogramannya lebih sulit dibanding dengan pengontrol lainnya seperti Arduino Uno yang lebih mudah pengoperasiannya [4].

Penelitian yang disusun oleh Deni Siswanto dan Slamet Winardi, masih sama seperti penelitian lain pada umumnya. Hanya saja pada penelitian kali ini menggunakan Arduini Uno sebagai pengontrolnya sehingga lebih mudah dalam perancangannya. Pada cara kerjanya juga mempunyai kesamaan yaitu, jika sensor cahaya mendeteksi adanya cahaya maka motor akan berputar dan menarik tambang keluar, sehingga posisi jemuran berada diluar, dan jika sensor cahaya tidak mendeteksi adanya cahaya maka motor akan menarik tambang jemuran untuk masuk, sehingga posisi jemuran berada didalam. Kekurangan pada penelitian diatas adalah Dalam proses ini maka ketika jemuran berada didalam tidak ada proses pengeringan pakaian dikarenakan tidak terkena sinar matahari atau sinar lainnya (kondisi hujan) [5].

Dalam perancangan dan pembuatan prototype yang dubuat menggunakan sensor cahaya (Light Dependent Resistor), Sensor Pendeteksi Air sebagai masukan mikrokontroler Arduino Uno, dan IC L298N sebagai penggerak motor yang terdapat pada penjemur pakaian. Hasil prototype penjemuir pakaian yang dihasilkan bekerja secara otomatis [6]. Sebuah prototype jemuran pintar merupakan inovasi terhadap kegiatan rumah tangga yang dirancang dan diimplementasikan dengan menggunakan hardware dan software Arduino Uno R3, sensor serta komponen elektronik lainnya. Prototype ini dibuat dengan bentuk miniatur jemuran pakaian yang dipasang dengan dua sensor yang berfungsi untuk mendeteksi keadaan cuaca, dengan kondisi terang dan gelap, serta lembab dan kering. Kerja sensor diatur oleh modul program yang sudah dibuat untuk menggerakkan sebuah motor, dimana modul ini dihubungkan langsung ke Arduino Uno R3 sesuai dengan perintah yang didapat dari senso [7].

Penelitian yang dilakukan oleh Adnan Feriska dan Dedi Triyanto tentang sebuah sistem kontroler yang dapat menjemur dan mengeringkan pakaian secara otomatis, jika kondisi cuaca hujan maka jemuran akan ditarik kedalam ruangan pengering untuk melakukan pengeringan pakaian. Pakaian mulai kering setelah kondisi kelembaban ruangan pengering semakin berkurang [8]. Penggunaan alat pengering secara 
otomatis yang menggunakan microcontroler Arduino Uno ditambah dengan sensor hujan dan sensor LDR (Light Dependent Resistor), untuk mendeteksi cuaca disekitar melalui sensor hujan dan sensor LDR, ketika sensor tidak menerima cahaya maka alat akan menterjemahkan akan terjadi hujan, sehingga alat akan menutup atap agar jagung terlindung dari air hujan. Ketika sensor mendeteksi sinar matahari alat akan menterjemahkan bahwa cuaca disekitar panas, sehingga alat akan membuka atap agar terkena sinar matahari. Sedangkan sensor hujan mendeteksi tetesan dari air hujan [9].

Dalam perancangan implementasi sistem jemuran otomatis, masalah-masalah yang dipecahkan adalah meliputi sistem pengendali jemuran, arsitektur perangkat keras, meliputi : perangkat elektronik dan mekanik dari keterangan diatas maka penulis padukan untuk merealisasi jemuran otomatis yang efektif dan efisien, dalam kesempatan penyusunan tugas akhir dengan judul Rancang bangun prototype penjemur pakaian otomatis berbasis Arduino Uno. Maka itu perlu dilakukan eksperimen rancang bangun alat penjemur pakaian otomatis berbasis Arduino. Alat yang dibuat ini lebih praktis, mudah dicari dan tidak menambah biaya mahal. Alat ini akan aktif bekerja masuk ket empat teduh yang disediakan saat hujan tiba atau malam menjelang, sehingga membantu untuk mempermudah pemakaiannya.

\section{METODE PENELITIAN}

Dalam penelitian ini menggunakan metode rancang bangun, yang diawali dari pembuata prototype jemuran otomatis, selanjutnya dibuatlah sistem kendali intensitas cahaya dan tetes air hujan sesuai dengan kebutuhan pada proses penjemur pakaian.

\subsection{Waktu Dan Tempat Pelaksanaan}

Penelitian ini dilakukan mulai bulan April 2017 sampai selesai, dengan mengambil tempat di laboratorium analog, Universitas Muria Kudus.

\subsection{Analisis Awal Metode Pengumpulan Data}

Untuk mengumpulkan data penelitian, penulis menggunakan dua metode yaitu :

a. Studi Kepustakaan

Penulis mencari dan mempelajari berbagai macam sensitifitas cahaya dan tetes air hujan baik itu text-books ataupun e-books.

b. Studi Eksperimen

Penulis melakukan eksperimen ataupun percobaan secara langsung dengan pengambilan data pada prototype alat penjemur pakaian otomatis berbasis arduino uno dengan menitik beratkan pada sensitifitas sensor cahaya dan tetes air hujan.

\subsection{Perancangan Penelitian}

Adapun Tahapan perancangan penelitian yang akan dilakukan debedakan menjadi beberapa bagian yaitu sebagai berikut :

a. Perancangan Hardware

Perancangan hardware bertujuan untuk merancang peralatan/rangkaian pendukung unruk sistem yang akan dibuat. Pada perancangan hardware terdpat alat dan bahan yang perlu dipersiapkan. Alat dan bahan yang digunakan dalam perancangan prototype alat penjemur pakain otomatis. Instrumen dan komponen Elektronika yang digunakan terdiri atas :

1. Arduino Uno

2. Sensor Cahaya

3. Sensor Hujan

4. Motor DC $12 \mathrm{Vdc}$

5. Power Supply $12 \mathrm{Vdc}$

6. Kabel Penghubung
7. Lampu Penerangan

8. Kipas Angin $12 \mathrm{Vdc}$

9. LCD

10. Lampu LED $12 \mathrm{Vdc}$

11. Limit Switch

b. Komponen bantu yang terdiri atas :

1. Papan plastik mika (Accrilyc).

2. Rel Jemuran

3. Rumah Jemuran

4. Kain

5. Benang Bol 
c. Spesifikasi Rancangan Alat

Spesifikasi alat yang akan dugunakan untuk membuat alat jemuran otomatis adalah sebagai berikut:

1. Menggunakan Arduino Uno sebagai pengendali.

2. Menggunakan LCD 2 x 16 untuk menampilkan cuaca yang sedang terjadi.

3. Sensor hujan yang digunakan sebagai alat untuk pendeteksi turunnya hujan.

4. Motor DC yang digunakan untuk menggerakan rel jemuran keluaran masuk ruangan, dengan spesifikasi: Tegangan Maksimal 12 Volt DC, Output rpm 322, Torsi Maksimal 0,5 kg, dan Gear Ratio 1:3.

5. Satu set jemuran yang terdiri dari beberapa bagian yaitu :

a) Satu buah rel jemuran dngan panjang $50 \mathrm{Cm}$

b) Tiang penyangga jemuran dengan tinggi $30 \mathrm{Cm}$

c) Tempat untuk menggantungkan jemuran yang sudah dimodifikasi

d) Rumah jemuran yang berfungsi untuk menyimpan jemuran pada saat turun hujan

e) 1 buah lampu dan 1 buah kipas angin $12 \mathrm{Vdc}$ sebagai media pengering jemuran pakaian didalam ruangan

f) Saklar untuk menghidupkan dan mematikan lampu LED.

g) Dua buah pulleyyang digunakan untuk menggulung tali penggerak jemuran

h) Satu buah saklar Microswitch yang digunakan sebagai pull-up.

\subsection{Perancangan Software}

Perancangan software dilakukan untuk memudahkan di dalam pengoperasian alat nantinya, yang perlu diperhatikan pada perancangan software adalah langkah pembuatan rancangan program, yang bisa dilihat Gambar 1.

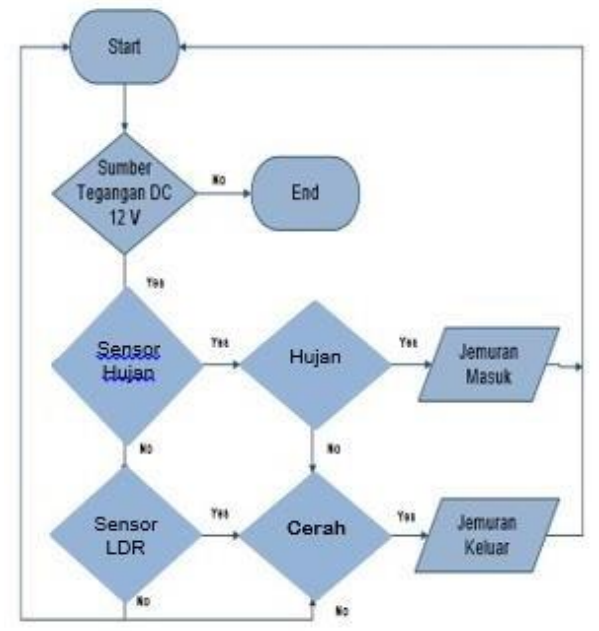

Gambar 1. Flowchart Alur Kerja Prototype Penjemuran Pakaian Otomatis

Pseudo Code Program software yang dirancang sebagai berikut.

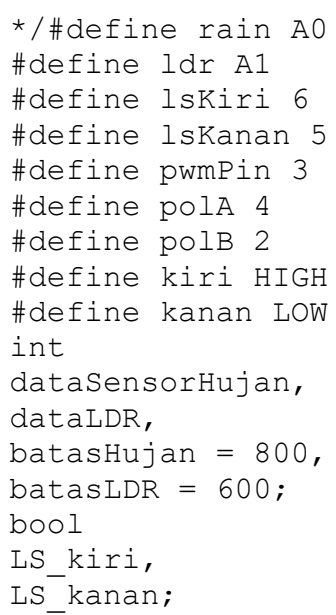




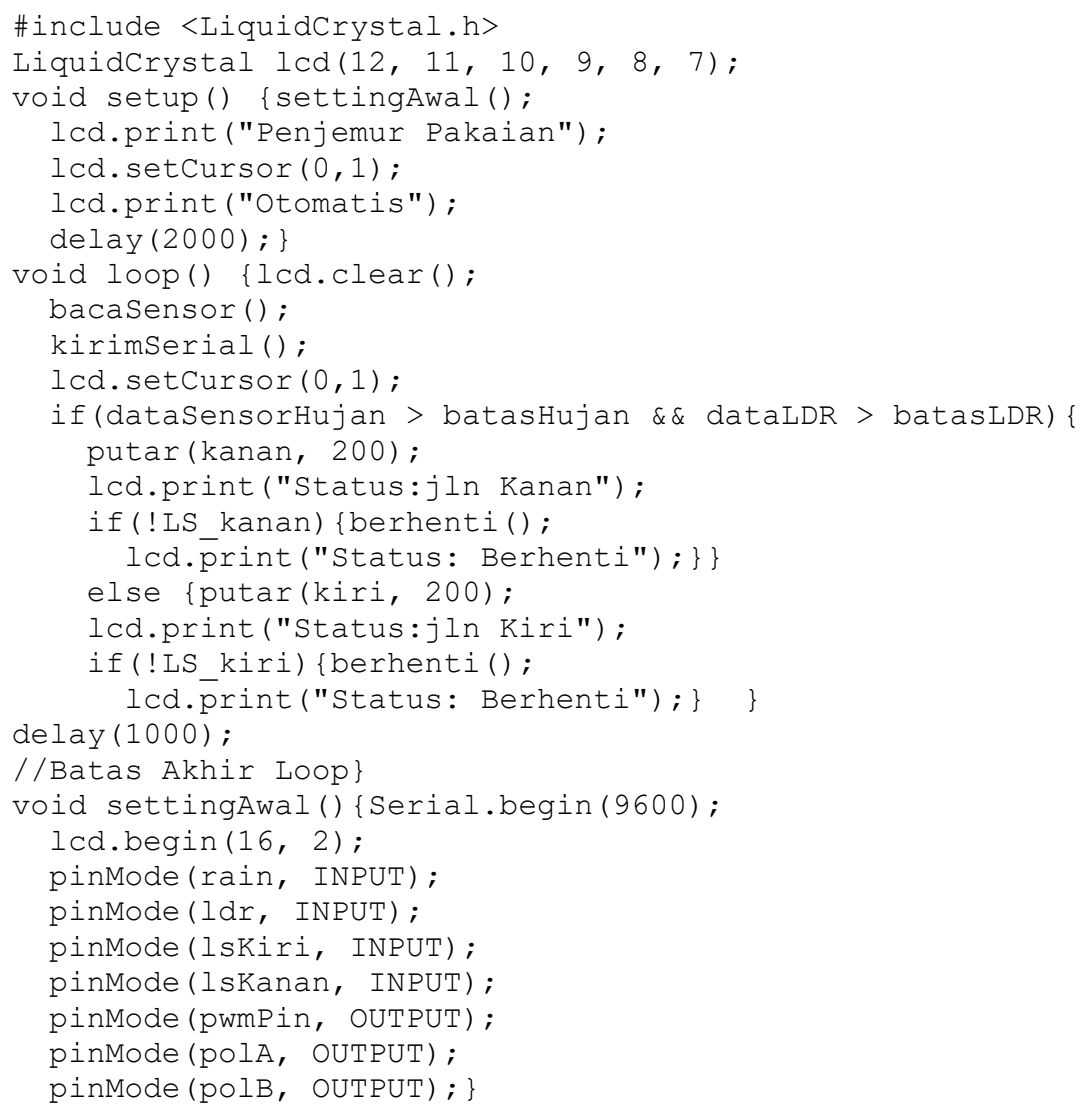

\section{HASIL PENELITIAN DAN PEMBAHASAN}

Prototype penjemur pakaian otomatis berbasis Arduino Uno dibuat supaya ketika turun hujan pakaian yang sedang di jemur tidak mengalami kehujanan dan basah terkena air. Pemanfaatan teknologi pada jemuran pakaian menciptakan sebuah jemuran pintar yang inovatif dalam kebutuhan rumah tangga yang dapat membaca kondisi cuaca sehingga secara otomatis dapat keluar dan masuk ke dalam rumah atau garasi rumah secara otomatis. Untuk dapat membaca keadaan cuaca, prototype jemuran pintar yang dibuat ini membutuhkan sensor cahaya (LDR) yang berfungsi sebagai pembaca keadaan cahaya disaat gelap dan terang, dan juga sensor air sebagai pendeteksi cuaca hujan.

Untuk melakukan uji coba alat penjemur pakaian otomatis dilakukan dengan berbagai kondisi yaitu dalam kondisi cerah, mendung, cerah tapi hujan, dan dalam keadaan hujan. Dimana pengujian dalam keadaan cerah sumber cahaya (lampu) tepat berada diatas sensor cahaya LDR dalam jarak yang sudah ditentukan, kemudian pengujian dalam keadaan mendung sumber cahaya (lampu) diredupkan atau dimatikan, selanjutnya pengujian dalam kondisi cerah tapi hujan sumber cahaya (lampu) berada tepat diatas sensor cahaya akan tetapi terdapat air yang mengenai sensor hujan, dan yang terakhir pengujian dalam kondisi hujan sumber cahaya (lampu) dimatikan dan diberikan air yang membasahi sensor cahaya.. Untuk lebih jelasnya dapat dilihat pada tabel 1 .

Tabel 1. Pengujian menggunakan sensor cahaya (Idr) dan sensor hujan

\begin{tabular}{ccc}
\hline \multirow{2}{*}{ Cuaca } & \multicolumn{2}{c}{ Hasil kerja alat penjemur pakaian } \\
\cline { 2 - 3 } Cerah & Jemuran Masuk & Jemuran Keluar \\
Mendung & OFF & ON \\
Cerah dan Hujan & ON & OFF \\
Hujan & ON & OFF \\
\hline
\end{tabular}

Dari data yang dihasilkan dari pengujian alat diatas dapat disimpulkan dan didapatkan analisis data tentang prototype alat penjemur pakaian otomatis berbasis arduino adalah dapat dibuat sebuah rancang bangun prototype alat penjemur pakaian otomatis berbasis arduino uno dengan sensor cahaya dan sensor hujan sesuai dengan yang direncana. Hasil pengujian alat penjemur pakaian otomatis menggunakan sensor cahaya dan sensor hujan, dapat di jabarkan sesuai dengan tabel kebenaran: dengan keadaan cuaca 
diluarcerah jemuran pakaian akan keluar (ON), dengan keadaan cuaca diluar mendung jemuran pakaian akan masuk (OFF), otomatis jemuran pakaian akan masuk kedalam ruangan, dengan keadaan cuaca diluar cerah dan hujan jemuran pakaian akan masuk (ON), otomatis jemuran pakaian akan masuk kedalam ruangan, dan dengan keadaan cuaca diluar hujan jemuran pakaian akan masuk (ON), otomatis jemuran pakaian akan masuk kedalam ruangan.

Pengujian alat penjemur pakaian otomatis menggunakan media senter sebagai pengganti matahari dengan jarak yang sudah ditentukan yaitu $25 \mathrm{~cm}$ dari sensor cahaya, dimana dalam keadaan cuaca mendung atau hujan penjemur pakaian beerada di dalam ruangan dan pada kondisi cuaca cerah pennjemur pakain bergerak menuju ke ruang terbuka. Pengujian prototype alat penjemur pakaian otomatis berbasis Arduino Uno dengan cara mendownload software program yang sudah dibuat ke dalam Arduino Uno dengan kabel serial, kemudian menguji sensor cahaya dengan media senter dan sensor hujan dengan media air. Pada saat jemuran pakaian berada di dalam ruangam tertutup maka secara otomatis kipas angin $12 \mathrm{Vdc}$ dan lampu LED 12 VDC akan aktif, karena ketika jemuran pakaian bergerak ke dalam ruangan tertutup akan menekan limit switch yang terpasang pada tiang penyangga sebagai ON/OFF dari Kipas Angin dan Lampu LED yang digunakan. Prototype alat penjemur pakaian otomatis berbasis arduino uno yang dibuat dapat berjalan sesuai dengan yang direncanakan tanpa masalah apapun yaitu jemuran pakaian berada diluar ruangan pada saat kondisi cerah dan berada didalam ruangan ketika kondisi cuaca mendung atau hujan.

\section{KESIMPULAN DAN SARAN}

Dari pembahasan di atas dapat disimpulkan bahwa: (1) Rancang Bangun Prototype Alat Penjemur Pakaian Otomatis Berbasis Arduino ini menggunaka sensor hujan (tetes air) dan sensor cahaya sebagai pendeteksi cuaca, yang digunakan untuk meringankan pekerjaan pengguna dalam menjemur pakaian. (2) Prototype Alat PenjemurPakaian Otomatis menggunakan motor penggerak DC dengan kapasitan 12 Vdc yang menggerakan tambang jemuran keluar dan masuk ruangan. (3) Pada proses rancang bangun Prototype Alat Penjemur Pakaian Otomatis Berbasis Arduino ini material yang digunakan untuk pembuatan struktur alat yaitu alumunium dan papan aklirik. (4) Perawatan dilakukan berkala agar mengetahui kerusakan yang terjadi pada Prototype Alat Penjemur Pakaian Otomatis Berbasis Arduino tersebut.

Saran untuk penelitian selanjutnya antara lain: (1) Pada saat pengoperasian, kondisi alat dipastikan siap beroperasi dan memperhatikan posisi peletakan alat pada alas yang kuat dan datar serta memperhatikan keadaaan kabel-kabel kontrol agar tidak mengganggu pada saat alat dioperasikan. (2) Pada saat pengujian, ketelitian dan fokus sangat diutamakan agar pengujian dapat berjalan dengan lancar dan tidak ada hambatan. (3) Membersihkan komponen Prototype menggunakan kain bersih dan sedikit basa h agar debu yang menempel hilang dan tidak melakukan perawatan perbaikan ketika sedang running. (4) Tidak menggunakan bahan karet sebagai tambang jemuran karena mempunyai media yang licin dan akan mengakibatkan selip sehingga jemuran tidak berjalan dengan maksimal.

\section{DAFTAR PUSTAKA}

[1] Laksono, A, B., Abidin. Z. 2014. “Perancangan Dan Pembuatan Alat Jemuran Otomatis Sensor Deteksi Basah”. Jurnal Teknik A. Vol 6 (2) , ISSN No. 2085-0859, Hal 593-596.

[2] Sitophila, S., Heriyanto, Hidayat, S. 2012. "Rancang Bangun Atap Sirip Otomatis Menggunakan LDR dan Sensor Tetes Air Hujan Berbasis Mikrikontroller". Jurnal-online.um.ac.id: 1-9. Fakultas Matematika dan Ilmu Pengetahuan Alam, Universitas Negeri Malang.

[3] Rismawan, E., Sulistyanti, S., dan Trisanto, A. 2012. "Rancang Bangun Prototype Penjemur Pakaian Otomatis Berbasis Mikrikontroller ATMega8535". JITET - Jurnal Informatika dan Teknik Elektro Terapan. Vol. 1 (1): 49-57.

[4] Mufida, E., Nurajizah, S., dan Abas, A. 2013. "Pengendali Atap Jemuran Otomatis dengan Sensor Cahaya Berbasis Mikrokontroller ATMega16". Konferensi Nasional Ilmu Sosial dan Teknologi: 269274.

[5] Siswanto, D., Winardi, S. 2015. “ Jemuran Pakaian Otomatis Menggunakan Sensor Hujan dan Sensor LDR Berbasis Ardiuno Uno”. e-Jurnal NARODROID. Vol. 1 (2015): 66-73.

[6] Hakim, A.R., Lailiyah, S., dan Suntoro, F., A. 2018. "Prototipe Penjemur Pakaian Otomatis Berbasis Arduino Uno". JUST TI. Vol. 10 (1): 16-21.

[7] Marpaung, N. 2017. "Perancangan Prototype Jemuran Pintar Berbasis Arduino Uno R3 Menggunakan Sensor Ldr dan Sensor Air”. Riau Journal Of Computer Science. Vol.3 (2): 71-80.

[8] Feriska, A., Triyanto, D. 2017. "Rancang Bangun Penjemur Dan Pengering Pakaian Otomatis Berbasis Mikrokontroler”. Jurnal Coding Sistem Komputer Untan. Vol. 05 (2): 67-76.

[9] Damastuti, N., Syafi'i, I. 2016. "Sistem Otomasi Atap Bangunan Pada Gudang Pengeringan Jagung Berbasis Arduino Uno”. e-Jurnal NARODROID. Vol. 2 (1): 111-116. 